\title{
Psychosocial Factors as Determinants of Vocational Skills Acquisition among Undergraduates in the University of Ibadan, Oyo State, Nigeria
}

\author{
Adeboye Titus Ayinde $\mathrm{PhD}$ \\ Department of Psychology, Obafemi Awolowo University \\ Ile-Ife, Nigeria
}

Tel: 234-803-601-9665, 234-802-829-4888

E-mail: ayindade@oauife.edu.ng; adedickson@yahoo.com

Received: September 8, 2016 Accepted: July 6, 2017 Published: August 10, 2017

doi:10.5296/ijld.v7i3.11671 URL: https://doi.org/10.5296/ijld.v7i3.11671

\begin{abstract}
The study examined self-esteem and socioeconomic status as determinants of vocational skills acquisition among undergraduates in the University of Ibadan, Ibadan, Oyo State. The study adopted descriptive survey design, 129 students were drawn as the sample from the university using the convenient sampling technique. Of the respondents, 58(45.0\%) were males and $71(55.0 \%)$ were females and the respondents' age ranged from 18 years to 27 years. Two standardised psychological test instruments were used namely: Hare Self-Esteem Scale and Gaur's Socio-economic Status Classification Scale and data collected was subjected to both descriptive and inferential statistical analyses. Two hypotheses were generated and tested at 0.05 level of significance. The findings from the first hypothesis reveal that self-esteem had the significant influence on vocational skills acquisition among undergraduates $(t=2.516>$ $\mathrm{t}-\mathrm{tab}=1.976, \mathrm{p}<0.05)$. However, the results of the second hypothesis revealed that socio-economic status had no significant influence on vocational skills acquisition among undergraduates $(\mathrm{F}(2,126)=0.182, \mathrm{p}>0.05)$. The study concluded that while self-esteem served as a determinant of vocational skills acquisition among undergraduates in the University of Ibadan, socioeconomic status did not affect their preference for vocational skills acquisition.
\end{abstract}

Keywords: Psychosocial factors, vocational skills acquisition, undergraduates, Nigeria 


\section{Introduction}

Vocational skills acquisition seems to appear as an antidote to sudden reality of unemployment among graduates of tertiary institutions in Nigeria in recent time. It has suddenly become a means of livelihood and a decent way of making earning living among this category of people. In fact, the preference for vocational skills acquisition alongside formal educational training may have become a sine qua non among undergraduates in tertiary institutions. Vocational skills acquisition, which is the acquisition of specific skills for self-employment or career, has become a major part of the average student's education plan (Ugwuja, 2010). Regardless of students' performance levels, vocational skills acquisition such as catering, dressmaking/fashion designing, bead making, web designing/graphics is prevalence in universities in Nigeria. The upside of vocational training is that the specific ability of individuals is utilised to the fullest (Tum, 1996). Vocational education, though just becoming increasingly accepted among students in Nigeria, has been around for a long while.

The courses that sprung up under earlier vocational skills training were industrial training, bookkeeping, stenography (shorthand) and commercial work. These courses were then offered both in private and public institutions. However, at this time, it is probable that vocational training was aimed at equipping the economically challenged youth with a 'sellable' skills to enable him to fend for himself and thus make a living (Hartl, 2009). In Africa, there are different systems of vocational education available from country to country. Training is provided in both private and public polytechnics, enterprises and apprenticeship training centres. It would seem, however, that in the last ten years, vocational training has shifted from being primarily in polytechnics and vocational schools to be quite rampant in the universities.

In Nigeria, a university degree in itself is no longer a guarantee for employment. Vocational training took a foothold in Nigeria in the last two decades. From that time till now, the number of interested individuals has doubled, tripled even (IFAD, 2008). Small scale businesses seem to be the order of the day and most of them were started while in pursuit of a university education. The Nigerian educational system provides students with the opportunity of learning a skill or craft after their third year in secondary school (Ngige, 2012). The introduction of such subjects as technical drawing, home economics, food and nutrition, fine arts and computer appreciation opens students up to the world of vocational skills acquisition and thus enables them at an early age to find a skill to which they are well suited. However, most students at this level find these subjects tedious and burdensome and thus display a negative attitude towards these subjects (Ngige, 2012).

Meanwhile, at the university level however, an average undergraduate comes to appreciate that a skill in catering or computer appreciation coupled with a degree from any department and different fields, may just very well be the difference between gaining employment speedily and sitting at home for years, hence, the increase in vocational skills acquisition among university undergraduates. The probable advantage of undergraduates' vocational skills acquisition in Nigeria, is reflected in the fact that industries and companies require a certain level of competence on the part of the employee. Such skills required for employment in most major companies nowadays include bookkeeping, computer literacy, event management, human 
resource management, project management, strategy formulation people skills etc. all of which can be acquired as part of one's undergraduate studies. It is, therefore, safe to infer that possessing a vocational skill of some sort makes an individual more employable or sellable.

A good number of factors have the propensity to influence the decision to engage in a vocational activity. Among such factors are self-esteem, socioeconomic status and even arguably grade point. For the purpose of this study, two of these factors; self-esteem and socio-economic status are considered. Self-esteem as generally defined refers to the individual's perception of his or her own worth or value. It is how the individual perceives himself or herself to be and oftentimes believes that others think of them in this same light. It is akin to self-worth and self-respect. If self-esteem serves as a determinant, can we, therefore, say that varying levels of self-esteem make certain individuals prone to excel in their academic pursuits and others to seek alternative means of attaining fulfilment and a sense of relevance through acquiring a vocational skill?

Another important factor is socio-economic status which often rises from the family background of the individual. It refers to the individual's social standing or position in the society as well as a number of financial resources at his or her disposal. An individual from a wealthy home will more likely have a higher standing in the society than one from a poorer home. The present study intends to examine whether a social rank will serve as a determinant in the acquisition of vocational skills. Will a closer look into the family backgrounds of a handful of students determine the students' interest in vocational skills acquisition? Invariably the study, on one hand, is interested to know if students from families where either or both parents possess a vocational skill or own a small scale business, are more likely to also deem it fit to acquire a vocational skills of their own?, and to know whether students from poorly homes engage in vocational skill training as a means of earning an income, improving their prospects and improving their social standing.

\section{Statement of the Problem}

Acquisition of vocational skills among university undergraduates, given the current levels of unemployment in Nigeria and what appears to be perceived fear of unemployment after graduation among university undergraduates, calls for attention. However, It is important to note that despite the seemingly numerous student participants in vocational training, not all undergraduates feel the need to learn a skill. This begs the question, 'what kind of students are prone to seeking the acquisition of a vocational skill?'

Moreover, several studies have been carried out regarding vocational skills acquisition and on a great number of factors that influence it. Such research looked into factors such as insufficient vocational education centres (Ngige, 2010), the effect of expository instructional strategies and gender on students skills acquisition (Nsa, Akpan, \& Williams, 2012), and factors affecting the vocational choice (Igbinedion, 2011), to mention a few. These studies found among other things a neglect of vocational training centres by the government or the community, unfavourable disposition towards vocational skills acquisition among undergraduates. However, little been done on the probable psychological factors which may affect the individual's perception of the need to acquire vocational skills. A review of previous 
literature also showed that peer pressure and the parental factor are among the factors examined by researchers as influencing vocational acquisition (Igbinedion, 2011); insufficient training centres, lack of trained personnel or teachers as well as living conditions of individuals and upbringing (Denga, 1990; Nwachukwu, 2003). In light of the current trends, where unemployment affects both the rich and the poor alike and people with certain employment opportunities still seek to acquire vocational skills (Awogbenle \& Iwuamadi, 2010). While much of the literature on this theme focused on external factors inhibiting or promoting the acquisition of vocational skills, the present study, therefore, considers the combination of psychological and social factors (self-esteem and socio-economic status) that can influence vocational skills acquisition among undergraduates, hence this study.

\section{Review of Empirical Studies}

One of the weaknesses of the Nigeria's education system is its failure to prepare graduates for self-employment and business entrepreneurship. The system encourages the graduates to follow the tradition of job seeking. The general notion is that a good job is a government job, and not a job in the private sector. In Nigeria currently, the economic environment has changed drastically so much so that the public sector is diminishing in job creation and economic liberalisation is taking place to the extent that public enterprises are being privatised thus making the private sector an engine of economic growth. Besides extolling the benefits derivable from entrepreneurship education, the article equally points out the likely impediments of this innovative educational practice. Various affirmative action programs for smooth implementation of entrepreneurship education in the university curriculum were adduced.

Denga (1990) stated that the economic situation or occupational level of one generation seems to remain like that of the previous generation. In most of the cases, the offspring of unskilled parents may choose their careers within the level but some may eventually rise. Thus, the offspring of businessmen and professionals tend to go for business and professional careers. In any case, there has been instance of many parents who are classified as low socioeconomic status families who have either acquired better education and occupy key posts in the society or their children have achieved the feat; such parents are often seen as strong motivating forces behind their children urging them to strive hard to become persons of substance such as doctors, engineers, pharmacists, lawyers, business executive or accountants, provided the children have the aptitude, intelligence and ability to cope with the high standard of education as pre-requisition for the careers.

Nwachukwu (2003) stated that boys from high income earning families tended to assume that they would go for higher Education and have occupational choice restricted to a professional executive type. And also found out that boys from lower-income families tended to prefer skilled jobs which offer higher years of study. It is common today to see youths born into either higher or low socio-economic families tending to look a career choice in terms of how real they are to them, what prestige is attached to such career and what satisfaction they can get from their careers. Shuell (1996) found out that the socio-economic background of a person has a link his/her educational and career development. He observed that students from high-income 
families tend to assume they would go to university, while students from lower income families tend to think in terms of skilled jobs. Vincent (1990) testifies that much of the child's educational development starts at home before he actually starts the formal education. Mulwa (2005) concludes that indiscipline among the pupils influenced poor performance. This is not different from skill acquisition in vocational and training centres. Mugambi (2006) notes that the entry marks of students to higher school learning institutions and training centres greatly influence performance and skill acquisition at the end of learning.

\subsection{Summary of the Literature Reviewed}

Much of the literature reviewed focused on the reasons why vocational institutions are not thriving and the role the government plays in this occurrence. Obscene rates of unemployment seem to be on the rise everywhere but especially in African countries and while getting a job with a government establishment might be easy, there is not enough room for the number of graduates turned out yearly by the university system. The private sector, attractive as it may seem, often requires individuals to possess a skill or group of skills different from his course of primary study; a set of vocational skills he is expected to have acquired as part of his education to bridge the gap in his knowledge of the job he has now applied for. The review of literature also showed that parents' socioeconomic status serves as a determinant for the career choice of individuals. Individuals from low socioeconomic background tend to opt for skilled jobs as this may seem more real to them and will help reduce their fear of unemployment after graduation. Being self-employed is a safer option for low socioeconomic status individuals as it beats pooling resources together and causing them to chase after paid employment that may not easily come by.

\subsection{Super's Theory and Vocational Skills Acquisition}

Vocational psychology is the term that Super (1954) and Woolfork (2004) chose to represent the field of study resulting from the fusion of the two streams of thought, i.e. occupations and careers. According to Super, career is enclosed in both the lifespan and the life-space, including life roles and lifestyle. His work is a unified set of theories dealing with specific aspects of career development, taken from developmental, differential, social, personality and phenomenological psychology and held together by self-concept or personal construct theory. Career maturity appears to be one of the major concepts in Super's theory which refers to the successful accomplishment of age and stage developmental tasks across the lifespan. Specifically, Super defines career maturity as A constellation of physical, psychological and social characteristics; psychologically, it is both cognitive and affective. It includes the degree of success in coping with the demands of earlier stages and sub-stages of career development especially with the most recent.

Super further explains that career maturity is an individual's readiness to cope with the developmental task with which he or she is confronted due to his or her biological and social development along with social expectations from those who have reached the stage of development. In short, career maturity is known as the peak of one's career. It is possible that there are several peaks or no peak at all for an individual. The five areas of career maturity are known as playfulness, exploration, information gathering, decision-making, and reality 
orientation.

According to Super's theory, the individual has a set of abilities and capabilities interests and capabilities which best suit him to a particular career or vocation choice. This choice is then made by the individual on the basis of his perception of those abilities and interests. If an individual chooses the right vocation for his person, he will attain satisfaction and fulfilment. If the individual, for instance, an undergraduate, is unable to gain a certain level of achievement in his chosen field, he then seeks an alternate. He often does this by acquiring a new skill or changing his vocation choice completely. Super states that vocational preferences are influenced by the situations in which people live and work. Hence, the family socio-economic status will play a major role in the vocational choice of the individual.

Super states that the process of vocational development relates to the development of a self-concept i.e. following a vocational path will help to create a sense of identity for the individual as the individual usually attributes who he is to what he does. The process of creating a vocational path inculcates both social factors and the concept of self. Super goes further to say that certain interests and abilities are inherited and then honed by the kind of life the individual has lived due to hard or rough circumstances. If the individual finds or chooses an appropriate vocation where he can achieve success and optimize his skills and abilities, he will attain satisfaction both in his work and in his life.

\subsection{The Needs Theories and Vocational Skills Acquisition}

These theories stress the desires, wants and circumstances which influence the individual in his choice of an occupation. Since individuals differ in personality and in their needs, different people enter into different occupations for different reasons. This would also apply that people acquire different vocational skills for different reasons. Maslow's hierarchy is illustrated in terms of a ladder showing from the lower level to the higher level and implied difficulty in moving from one stage to the other. The needs are physiological needs (good food, shelter, security), affiliate needs (love and affection), self-enhancement needs (need for progress and achievement); self-expression needs deal with when the individual wants to excel and have the awareness of the needs of others, self-actualization needs (the individual looks back and counts what he has done with his life). All these needs motivate and influence what an individual does in life as well as value he/she places on things around them. Maslow believed that man is inherently good and argued that individuals possess a constantly growing drive that has great potential. The needs hierarchy system, devised by Maslow (1954), is a commonly used scheme for classifying human motives.

The implications of this theory to the present study are numerous; for instance, undergraduates would be responding to self-enhancement needs when they consider acquisition of vocational skills alongside formal education. That is, students' motive for learning petty trade or various arts while still in school may not be unconnected with the desire to put themselves at advantages for competition for a few jobs that may be available or to be self-sustained even after their study. Apart from the need for achievement and desire to make progress, the need for self-expression may also spun individuals to do extra thing beyond their conventional activities. An undergraduate would readily hone or salvage whatever ability he or she is endowed with in 
order to make a difference. All these motives combined together can explain the drives for vocational skills acquisition among undergraduates of tertiary institutions in Nigeria.

\section{Methodology}

This study employed a descriptive research design to establish a pattern among variables of interest and to provide numerical description of sample of the population. The independent variables in this study are self-esteem and socio-economic status, while the dependent variable is vocational skills acquisition. Self-esteem has two levels; low and high while socio-economic status has three levels; high, moderate and low, and vocational skills acquisition has to levels respectively.

\subsection{Population and Sample}

The study population consisted of undergraduates at the University of Ibadan, Ibadan, Oyo State. The total student population of this institution is averaged at 33,481 (Wikipedia, 2015). The choice of this population of undergraduates was due to the increasing number of undergraduates who have difficulty in getting employment after graduation. The sample of undergraduates drawn for the study consisted of 150 students. The sample was conveniently drawn and it represents students from different faculties and departments as well as in different years of study.

\subsection{Research Instrument}

Section A of the questionnaire required basic general knowledge of the respondent such as age, gender, marital status etc. It did not ask for the respondents' name so as to allow them remain anonymous. For this study, Section A included: gender, age, level or class in university, department, faculty, nationality and vocational skills acquired (if any).

\subsection{Hare Self-Esteem Scale}

Section B measures the self-esteem of the respondent. It employed the Hare Self-Esteem Scale (HSS). The HSS consisted of three 10-item subscales that are area specific (peer, school and home); totaling 30 items. For the purpose of this study, only two subscales were used (school and home), totaling 20 items. The scale adopts a 4-point Likert scale; SA= Strongly agree, $\mathrm{A}=$ agree, $\mathrm{D}=$ disagree and $\mathrm{SD}=$ Strongly disagree. The Likert scale score as $\mathrm{SA}=3, \mathrm{~A}=2, \mathrm{D}=1$, $\mathrm{SD}=0$. The respondents were then to tick for each item on the scale, the option (SA-SD) that best qualifies their answer. The results were then summed up. A higher score indicates a higher self-esteem and vice versa.

\subsection{Socio-Economic Status Scale}

Gaur's Socio-Economic Classification Scale was employed to measure socio-economic status in this section. Section $\mathrm{C}$ measures the socio-economic status of the respondent by measuring educational qualification, occupation and monthly income of the respondent's family (parents). Gaur's scale was modified from the original 32 items in four sections (education, occupation, income per capita income and expenditure) to just 20 items (with the exclusion of expenditure). The 20 items were then subdivided into educational qualification, occupation and income per 
capita per month (monthly income), with 7 items in each subsection. The respondents then picked one item in each section for each parent's (mother and father) educational qualification, occupation and monthly income (approximate monthly income). The scoring goes from 0-7 where 0 is the lowest qualification level or income and 7 the highest. The scores were then summed up and a high score indicates a high socio-economic status while a low score indicates a low socio-economic status.

\subsection{Validity and Reliability of the Research Instrument}

In ascertaining the validity of the Hare Self-esteem Scale (HSS), it was correlated with both the Cooper Smith Self-esteem Inventory and the Rosenberg Self-esteem Scale. The HSS general scale correlated .83 with both scales indicating excellent concurrent validity. The HSS subscales also correlate significantly with changes in life status and with predicted area-specific activities. In testing the reliability of the HSS, no internal consistency data are reported. Test-retest correlations indicate good stability, with three-month correlations ranging from .56 to .65 for the three subscales and .74 for the general scale. Gaur's socio-economic classification scale's reliability was determined by the test-retest method. The content validity was tested of proposed SES scale by the opinion of subject experts. It was again observed in relation to Visual Analogue Scale score for SES. The validity was found to be 0.97.

\subsection{Administration of the Research Instrument}

The questionnaire was administered personally by hand to the respondents at their various places of residence within the University of Ibadan. A total of 150 questionnaires were administered by the researcher. Of this number, only 129 questionnaires were found valid for this research; 12 of the questionnaires were found invalid or incorrectly filled and the remaining 9 were lost in the field i.e. not returned by the respondents.

\subsection{Treatment of Data}

Descriptive statistics was used to analyse the data generated from the socio-demographic variables while the first hypothesis was tested with an independent sample t-test and the second hypothesis was tested using one way analysis of variance. The association between the independent and dependent variables was established and both hypotheses were tested at $0.05 \%$ level of significance.

\section{Results Analysis}

\subsection{Descriptive Analysis}

One hundred and twenty-nine (129) comprising 58 (45.0\%) of male and 71(55.0\%) of female undergraduates of University of Ibadan across the different levels participated in the study. There are $10(7.8 \%)$ students in 100level, $14(10.9 \%)$ students in 200level, $26(20.2 \%)$ are in $300 l e v e l, 52(40.3 \%)$ are in 400level, $26(20.2 \%)$ are in 500levels respectively. Respondents were mostly between $19-23$ years of age.

\subsection{Hypothesis Testing}

Hypothesis One: The hypothesis states that there will be a significant influence of self-esteem 
on vocational skill acquisition.

The hypothesis was tested using an independent sample t-test. The analysis process involves categorising respondent's scores on self-esteem into high and low. Then the low self-esteem scores were compared with those of high self-esteem on vocational skills, the summary of the analysis is presented in Table 1.

Table 1. Summary table of independent sample t- test table showing influence of self-esteem on vocational skills

\begin{tabular}{lllllllll}
\hline Variables & & $\boldsymbol{N}$ & $\bar{X}$ & $\boldsymbol{S D}$ & $\boldsymbol{d f}$ & $\boldsymbol{t}$-cal & $\boldsymbol{t}$-tab & $\boldsymbol{p}$-val \\
\hline $\begin{array}{l}\text { Vocational } \\
\text { skills }\end{array}$ & Low-esteem & 21 & 2.05 & 1.02 & & & & \\
\cline { 2 - 6 } & High-esteem & 108 & 2.58 & 0.87 & & & & \\
\end{tabular}

$(t-c a l=2.516>t-t a b=1.976, p=0.013)$.

Table 1 reveals that there is a significant influence of self-esteem on vocational skills acquisition among undergraduates of the University of Ibadan, Ibadan $(t-c a l=2.516>$ $t$-tab $=1.976, p=0.013$ ). Therefore, the alternate hypothesis which states that there will be a significant influence of self-esteem on vocational skill acquisition is accepted.

Hypothesis Two: Hypothesis two states that there will be a significant influence of socioeconomic status on vocational skills acquisition.

The hypothesis was tested using One Way Analysis of Variance. Respondents' socioeconomic status was categorised into three (high, moderate and low) and the three groups scores on vocational skills were subjected to test of comparison, the analysis is presented in Table 2.

Table 2. Summary table of One Way ANOVA, showing Influence of Socioeconomic Status on Vocational Skills

\begin{tabular}{llllll}
\hline Groups & Sum of squares & Df & Mean square & F-val & P-val \\
\hline Between Groups & .305 & 2 & .153 & & \\
Within Groups & 105.943 & 126 & .841 & .182 & .834 \\
Total & 106.248 & 128 & & & \\
\hline
\end{tabular}

$(F(2,126)=0.182, p=0.663)$ 
Table 2 showed that there is no significant influence of socioeconomic status on vocational skills acquisition among undergraduates $(F(2,126)=0.182, p>0.05)$. The result showed that study participant with high, moderate and low socioeconomic status has a similar level of vocational skills acquisition. The hypothesis which states that there will be a significant influence of socioeconomic status on vocational skills acquisition is therefore rejected and the null hypothesis is accepted.

\section{Discussion}

Hypothesis one stated that self-esteem would have a significant influence on vocational skills acquisition among undergraduates. The finding showed a significant influence of self-esteem on vocational skills acquisition among undergraduates. This implies that undergraduates with high self-esteem acquired vocational skills more than individuals with a low self-esteem. Wilkinson (1999) states that self-esteem is affected by factors such as low income, unemployment, and poor basic skills. Hence, he believes that individuals with low self-esteem will ultimately lack the basic skills required to acquire a vocational skill and will thus not seek to acquire vocational skills. This corroborates the findings of this study which showed that individuals with a low self-esteem are less likely than individuals with high self-esteem to acquire vocational skills. This study, therefore, shows that not only does self-esteem have a significant influence on vocational skill acquisition among undergraduates but that vocational skill acquisition requires a high self-esteem.

Super and Thompson (1979), also found that the tendency of an individual to acquire vocational skills is determined not only by the individual's education or mental ability but also by his self-esteem, personality and parental socio-economic level. Isaac (2011), corroborates Thompson's findings. He states that the decision of an individual in making a vocational choice is usually greatly influenced by many factors including his aptitudes and abilities and self-esteem. According to the self-determination theory, self-confidence of students in their own capacities and attributes promotes an interest in learning new skills (Deci \& Ryan, 1985, 1991). Hence, it goes to show that acquiring a new vocational skill requires a certain level of self-esteem or confidence that one can cope with the challenges of learning and be applying something new. This study shows that among undergraduates in the University of Ibadan, only those with a high self-esteem were found to have acquired a vocational skill ranging from dressmaking to catering and even photography. However, practitioners in further education strongly believe that individuals gain self-esteem from learning (Preston and Hammond 2002). This varies from previous studies such as Wilkinson's (1996) study on self-esteem and vocational skill acquisition and the present study which states that a high self-esteem is required for the acquisition of a vocational skill. Preston and Hammond rather state that learning a vocational skill is useful for the individual with low self-esteem as it will help build their self-esteem.

Hypothesis two addressed the influence of socio-economic status on vocational skills acquisition among undergraduates. This study shows that socio-economic status is not a determinant factor for vocational skills acquisition as undergraduates from both high, moderate and low socio-economic status would engage in the acquisition of a vocational skill. This 
implies that among undergraduates in the University of Ibadan, socio-economic status played no significant role in vocational skills acquisition. This finding finds support in the study of Denga (1990), who states that there have been multiple instances of many individuals who are classified as having low socio-economic status, who have either acquired better education and occupy key posts in the society or their children have achieved the feat; such parents are often seen as strong motivating forces behind their children urging them to strive hard to become persons of substance such as doctors, engineers, pharmacists, lawyers, business executive or accountants, provided the children have the aptitude, intelligence and ability to cope with the high standard of education required of them. However, the finding is in contrast with that Nwachukwu (2003) who stated in his work that boys from high income earning families tended to assume that they would go for higher Education and have occupational choice restricted to a professional executive type. And also found out that boys from lower-income families tended to prefer skilled jobs which offer higher years of study.

\section{Summary of the Study}

This study sought to determine the influence of self-esteem and socio-economic status on vocational skills acquisition among undergraduates in the University of Ibadan. This was with a view to answering a number of research questions and to meet the stated objectives. The study was presented in five chapters. The introductory chapter presented the background to the study, the statement of problem, objectives, significance and scope of the study and definition of terms. The introductory chapter was followed by a review of relevant literature in chapter two. It covered a review of concepts and relevant theories, empirical review of literature and statement of hypotheses. The third chapter dwelled on methodology. It provided information on the research design adopted, population and sample as well as the research instrument applied. Two major scales were used for this study; the Hare Self-Esteem Scale (HSS) to measure self-esteem and Gaur's Socio-Economic Classification Scale which was used to measure socioeconomic status. The procedure for gathering data was also discussed. Chapter four contained the results of descriptive analyses and hypotheses testing. The results of the analyses showed the following;

i. Self-esteem influenced vocational skills acquisition among undergraduates of University Ibadan;

ii. Socio-economic status did not influence vocational skills acquisition among undergraduates of the University of Ibadan.

\section{Conclusion}

From the analysis of the data collected and interpreted, the results show that while self-esteem has a significant influence on vocational skills acquisition among undergraduates, socio-economic status has no significant influence on vocational skill acquisition among undergraduates. Contrary to popular belief, this study has shown that a low socio-economic status is not a determinant of vocational skill acquisition as both participants from low and high socioeconomic backgrounds acquired vocational skills. However, the study showed that low self-esteem can affect the perception of the need for acquisition of vocational skills acquisition 
as more participants with a high self-esteem expressed intention to acquire vocational skills.

\section{Implication of the Study}

The findings of the study indicate that while self-esteem has a significant influence on vocational skills acquisition, socio-economic status does not have any influence on vocational skill acquisition among undergraduates in the University of Ibadan. The results, therefore, imply that undergraduates with high self-esteem are more likely to acquire a vocational skill than those with low self-esteem. It also implies that undergraduates regardless of their socio-economic status will often engage in vocational skill acquisition. This study is thus able to contribute to the theoretical literature on vocational skill acquisition, self-esteem and socio-economic status. Previous studies laid more emphasis on the willingness or lack of enthusiasm among undergraduates towards the acquisition of vocational skills. This study, however, looked into psychosocial factors which may be perceived as responsible for the acquisition of a vocational skill. It is, however, important to suggest that despite the findings of this study, the issue of psychosocial factors influencing vocational skill acquisition, should be further looked into.

\section{Limitation to the Study}

One of the major limitations to this study was the unwillingness of undergraduates to participate in the survey carried out by filling out questionnaires. The majority had to be persuaded to fill out the questionnaires and to do so correctly. The major complaints of the proposed respondents were that they disliked filling questionnaires or that the questions were too many or too complex to understand at first glance. Perhaps, this explains low numbers of respondents in this study. Another limitation was the time frame provided for the administration of questionnaires and collection of data.

\section{Recommendation of the Study}

Based on the findings from the study and coupled with the increasing rates of unemployment in Nigeria, recommendations are suggested as follows; undergraduates of low self-esteem should be encouraged to acquire a vocational skill as mastering a new skill or task will help develop self-confidence in themselves and in their capabilities. Also, vocational skills acquisition should be included in undergraduates' university education as this will serve to influence them to acquire vocational skills which will, in essence, serve to reduce unemployment. Furthermore, the Government has a role to play in setting up vocational centres and subsidising the rates will help undergraduates of both high and low socio-economic status acquire a vocational skill at an affordable price. These centres set up should regardless of the subsidised tuition rates, have adequate facilities for learning as well as capable instructors. The creation of these centres will also create job opportunities as instructors and managers will be needed for the smooth running of these vocational centres; thus reducing unemployment as well. Successful students from vocational centres should be given incentives as this will encourage others to engage in the acquisition of vocational skills. 


\section{References}

Awogbenle, A. C. \& Iwuamadi, C. (2010). The youth unemployment: Entrepreneurship development programme as an intervention mechanism. African Journal of Business Management, 4(6), 831-835.

Deci, E. L., \& Ryan, R. M. (2000). The "what" and the "why" of goal pursuits: Human needs and the self-determination of behaviour. Psychological Inquiry, 11, 227-268. https://doi.org/10.1207/S15327965PLI1104_01

Deci, E. L., \& Ryan, R. M. (1991). A motivational approach to self: Integration in personality. In R. Dienstbier (Ed.), Nebraska symposium on motivation: Vol. 38, Perspectives on motivation (pp. 237-288). Lincoln: University of Nebraska Press.

Denga, D. (1990). Educational and Vocational Guidance in Nigeria Secondary Schools. Enugu, Nigeria, Rapid Educational Publishers Limited.

Hartl, M. (2009). Technical and vocational education and training (TVET) and skills development for poverty reduction- do rural women benefit? International Fund for Agricultural Development, Italy.

Igbinedion, V. I. (2009). Gender enrollment pattern in secretarial studies programs in tertiary institutions in the Edo state of Nigeria (M. Ed Project. University of Benin).

International Fund for Agricultural Development (IFAD). Technical and vocational skills development for poverty alleviation. Report of the International Consultation.

Isaac, N. (2011). Skills Acquisition, Tonic for Economic Empowerment. Leadership Newspaper, Retrieved May 13, 2014.

Maslow, A. H. (1954). Motivation and Personality. New York: Harper and Bros. https://doi.org/10.1111/j.1467-6494.1954.tb01136.x

Mugambi, G. K. (2006). Performance contracting in Kenyan Secondary Schools. Prime Journal of Business Administration and Management, 4(2), 1369-1374.

Mulwa, F. W. (2005). Demystifying participatory development. Zapf Chancery Tertiary Level Publications.

Ngige, R. A. (2012). Factors affecting acquisition of vocational skills among youth learners in Maranda Division Siaya County. Preliminary pages, 1, 1-3.

Nsa, S. O., Akpan, E. O., and Williams, P. S. (2012). Instructional Strategies and Students' Skill Acquisition in Vegetable Crop Production. Pakistan Journal of Business and Economic Review, 5(8-1), 163-167.

Nwanchukwu, F. J. (2003). Organisation and Administration of Guidance Services. Owerri, Nigeria: Reliable Publishers..

Preston, J and Hammond, C. (2002). The Wider benefits of learning: Practitioners Views. The 
Centre for Research on the Wider Benefits of Learning. Research Reports March.

Shuell, T. (1996). Teaching and Learning in a Classroom Context: Handbook of Educational Psychology. New York, Macmillan.

Super, D.E. \& Thompson, A. S. (1979). A six scale, two factor, a measure of adolescent career or vocational maturity. Memorandum, XIX International Congress of Applied Psychology, Munich. https://doi.org/10.1002/j.2164-585x.1979.tb00078.x

Tum, P. C. (1996). Education trends in Kenya: A vocational perspective. Nairobi: Jomo Kenyatta Foundations.

Ugwuja, S. I. (2010). 'Vocational Technical Education and Development' NBF News. Retrieved November 7, 2011, from http://www.nigerianbestforum.com.blog.

Vincent, J. D. (1990). The Biology of Emotions. Cambridge, Mass Basil Blackwell.

Wilkinson, R.G. (1996). Unhealthy Societies. The Afflictions of Inequality (1st ed.). London, Routledge,

Woolfolk A. E. (2004). Educational Psychology. $3^{\text {rd }}$ Edition, Boston, Allyn and Bacon, USA. https://doi.org/10.4324/9780203421680

\section{Copyright Disclaimer}

Copyright for this article is retained by the author(s), with first publication rights granted to the journal.

This is an open-access article distributed under the terms and conditions of the Creative Commons Attribution license (http://creativecommons.org/licenses/by/4.0/). 